Abstract P3.310 Table 1 (Continued)

\begin{tabular}{|c|c|c|c|}
\hline & \multicolumn{2}{|c|}{$\begin{array}{l}\text { NHBS* } \\
\text { N \% (95\% CI) }\end{array}$} & $\begin{array}{l}\text { SFCC* } \\
\text { N \% (95\% CI) }\end{array}$ \\
\hline \multicolumn{4}{|c|}{ CHLAMYDIA (PAST YEAR) } \\
\hline NO & 468 & $93.0 \%(90.4-95.1)$ & $87.8 \%(86.2-89.3)$ \\
\hline YES & 35 & $7.0 \%(4.9-9.5)$ & $12.2 \%(10.7-13.8)$ \\
\hline \multicolumn{4}{|c|}{ GONORRHEA (PAST YEAR) } \\
\hline NO & 458 & $90.7 \%(87.8-93.1)$ & $88.6 \%(87.0-90.0)$ \\
\hline YES & 47 & $9.3 \%(6.9-12.2)$ & $11.4 \%(10.0-13.0)$ \\
\hline \multicolumn{4}{|c|}{ SYPHILIS (PAST YEAR) } \\
\hline NO & 494 & $97.8 \%(96.1-98.9)$ & $95.2 \%(94.1-96.1)$ \\
\hline YES & 11 & $2.2 \%(1.1-3.9)$ & $4.8 \%(3.9-5.9)$ \\
\hline
\end{tabular}

* Column totals do not sum to sample totals because of missing values.

municipal STD clinic might serve as a proxy population during nonsurvey years.

Methods We compared select questions from the 510 participants of the NHBS MSM-San Francisco survey (07/21-12/19/2011) to similar measures from 1807 MSM who visited the San Francisco City Clinic (SFCC) during the same time period. One visit was randomly selected among clients who had multiple SFCC visits during the study period. We compared the two groups' demographics and HIV/STD-related history. Data were self-reported except SFCC STD history, which was laboratory-confirmed.

Results SFCC clients were more likely to be younger, non-white, un-insured, and self-identify as straight. NHBS participants were more likely to report a lifetime history of injection drug use and 12-month non-injection drug use of cocaine, crack, poppers, and erectile dysfunction medications. Methamphetamine use was not statistically different. Approximately $44 \%$ of both samples reported $\geq 6$ male partners in the past year. The two groups did not differ on history of HIV testing, HIV-positive status, current HAART use among known HIV positives, or PEP use in the past year among HIV negatives. Self-reported syphilis or chlamydia was less likely among NHBS participants than laboratory-confirmed diagnoses among SFCC clients; gonorrhoea positivity did not differ statistically.

Discussion NHBS and SFCC MSM similarly reported several key behavioural surveillance factors. Readily available non-survey surveillance data may be useful for monitoring trends among the San Francisco MSM population and informing policy and programmes. Future efforts should explore how STD clinic data can be used to supplement behavioural surveillance.

\section{P3.311 ASSESSMENT OF HIV PREVALENCE AND SEXUAL BEHAVIOURS AMONG MEN WHO HAVE SEX WITH MEN IN CYPRUS, 2011-2012}

doi:10.1136/sextrans-2013-051184.0765

${ }^{1} \mathbf{M}$ Pylli, ${ }^{2} \mathrm{~V}$ Raftopoulos, ${ }^{2} \mathrm{~N}$ Middleton, ${ }^{2} \mathrm{~A}$ Charalambous, ${ }^{1} \mathrm{D}$ Paraskeva. ${ }^{1}$ Hellenic Center for Disease Control and Prevention-HCDCP, Athens, Greece; ${ }^{2}$ Cyprus University of Technology, Nursing Department, Limassol, Cyprus

Background Men who have sex with men (MSM) comprise the most vulnerable group for HIV infection.

Aim of this study was the estimation (1) of HIV prevalence and (2) sexual behaviours among MSM in Cyprus.

Sample and Methods time location sampling has been used to recruit a representative sample of MSM in Cyprus during January 2011 to January 2012. Self completed questionnaires and Orasure oral fluid collection kits were distributed to men who were frequented in gay venues. Ethical approval was obtained by the Cyprus National Bioethics Committee.
Results $200 \mathrm{MSM}$ participated in the study. The response rate was quite high (89\%). HIV prevalence was $2.5 \%$. The mean age was $29 \pm$ 6.6 years old while $74.9 \%$ of MSM identified themselves as gay. The prevalence of last unprotected anal intercourse was $30 \%$ while the last unprotected oral sex was $87.7 \%$. The percentage of the participants who reported they have used alcohol and cocaine before or during the last sexual contact were around $60 \%$ and $10 \%$ respectively. One out of three has not been tested for HIV the last 12 months neither they know where they can get tested for HIV. Concerning HIV transmission modes knowledge, 22\% of MSM answered correctly in the 5 questions, according to UNGASS guidance. In the univariate analysis, cocaine use, education level and type of sexual partner were independently associated with the unprotected anal intercourse.

Conclusion The prevalence of HIV infection in MSM in Cyprus remains stable at low levels similar to other Central European countries. The high response rate indicates the broad acceptance of such studies. Knowledge awareness campaigns should be implemented regarding the transmission modes and risky sexual behaviours as well as interventions for the promotion of HIV testing.

\section{P3.312 STI/HIV ASSESSMENT IN MAIN TRANSPORT CORRIDORS ALONG DJIBOUTI TO ADDIS ABABA}

doi:10.1136/sextrans-2013-051184.0766

${ }^{1}$ A K Woldemichael, ${ }^{2} \mathrm{~F}$ Alwan, ${ }^{1} \mathrm{~A}$ Hassen. ${ }^{1} / R A P P$, Kampala, Uganda, ${ }^{2} I G A D$, Djibouti, Djibouti

Background There are very limited number of literatures on crossborder communities and HIV/AIDS. The objective of this study is to assess the situation of HIV/AIDS among populations in the main transport corridors along Djibouti to Addis Ababa.

Methodology The study was conducted in three hot spots along Djibouti to Addis Ababa rout, namely. Both qualitative and quantitative approaches employed in order to explore HIV/STI situations. Result A total of 120 truck drivers and their assistance were interviewed at 3 hot spots. $81.7 \%$ were truck drivers and $18.3 \%$ were truck drivers' assistants. A wide variety of health problems were reported; of all Malaria (98.3\%), STI (81.1\%), URTI (65.1\%) and diarrhoea (63.3\%). From all participants, $31.7 \%$ could not identify any STI symptoms, while the rest, $28.3 \%, 14.2 \%$ and $5.8 \%$ of them were known one, three and five symptoms, respectively. $48.3 \%$ of the participants have sought treatment, of whom $81 \%$ of them were treated at private clinics.

The majority of FSWs are mobile with truck drivers (38.3), and 31.7 of them were not travel with truck drivers. The FSWs clients found to be truckers, port workers, uniformed services, government employee. Common health problems reported by FSWs were STI (95.2\%), HIV/AIDS (74.8\%), and malaria (22.1\%). As symptoms, genital sores identified by $40 \%$, vaginal discharge by $60 \%$, burning sensation by $70 \%$.

Conclusion The highways were carrying relatively high volumes of traffic. Mobility of truckers and FSWs was high. Transactional sex is already at high level and condom use is low. There were high prevalent of self reported cases of STIs by truckers and FSWs. There is a need for targeted HIV programmes for FSWs and Truckers.

\section{P3.313 COMPARISON OF PSYCHOPATHOLOGICAL DIMENSIONS IN SUBSTANCE ABUSERS WITH AND WITHOUT HIV/AIDS AND HEALTHY MATCHED GROUP}

doi:10.1136/sextrans-2013-051184.0767

'S Taramian, ${ }^{2} \mathrm{~S}$ Rezaei, ${ }^{3} \mathrm{M}$ Kafi, ${ }^{3} \mathrm{~F}$ Pooragha, ${ }^{4} \mathrm{~N}$ Bazarganian. 'Gilan University of Medical Sciences, Rasht, Iran; 'Department of Psychology, University of Isfahan, Isfahan, Iran; ${ }^{3}$ Gilan University, Rasht, Iran; ${ }^{4}$ Gilan University of Medical Sciences, Clinic of Behavioral Diseases, Rasht, Iran 